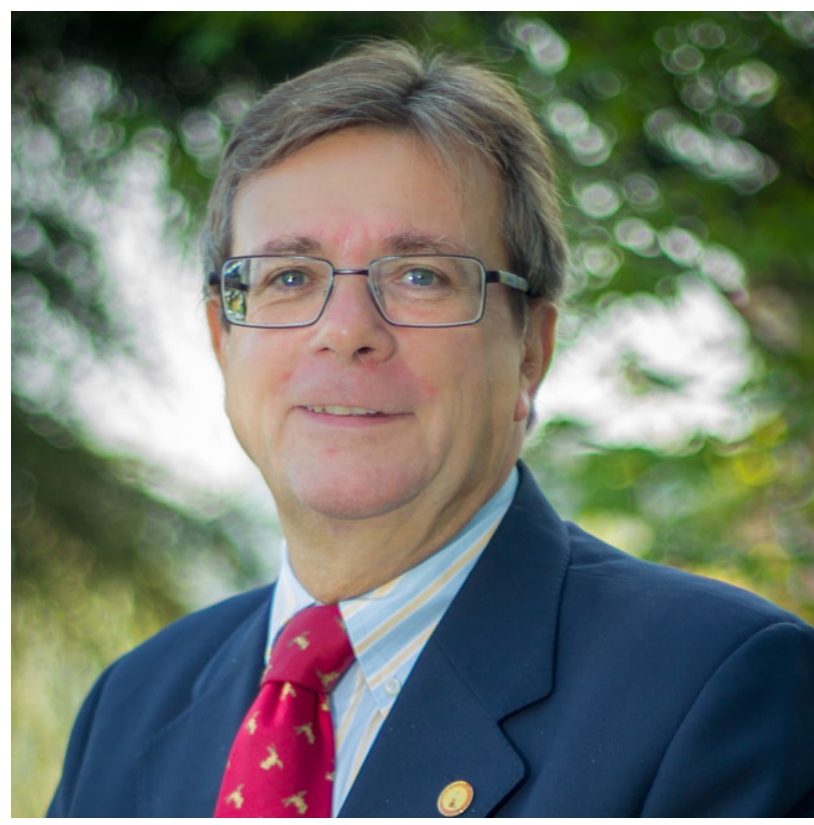

\title{
Entrevista al Dr. Julio Cabero Almenara
}

\author{
Por su ardua labor educativa \\ ha recibido el Premio de la Real \\ Maestranza de Caballería.
}

El Dr. Julio Cabero Almenara es catedrático de Didáctica y Organización Escolar de la Universidad de Sevilla. Es director del SAV (Secretariado de Recursos Audiovisuales y Nuevas Tecnologías) de esta universidad y miembro fundador de Edutec. Por su labor educativa ha recibido el Premio de la Real Maestranza de Caballería.

Ha publicado diferentes obras sobre la temática de la tecnología educativa y las nuevas tecnologías aplicadas a la educación (Tecnología Educativa. Diseño y utilización de medios en la enseñanza, Paidós, 2001; Nuevas tecnologías aplicadas a la educación, Síntesis, 2000; La imagen del profesor y la enseñanza en los medios de comunicación, Universidad de Sevilla, 1998).

El Dr. Cabero ha impartido innumerables conferencias en varias universidades españolas y latinoamericanas, incluyendo a la República Dominicana, y también ha colaborado con la creación y seguimiento de doctorados en Educación. Por su tesonera labor y su alto impacto podemos considerarlo el apóstol de la tecnología educativa y la innovación.

\section{1. ¿Aun siendo del área de didáctica y filosofía cómo se inició en el mundo de la tecnología educativa?}

En los estudios de Pedagogía había una asignatura que se denominaba Tecnología Educativa, era una asignatura optativa que se podía cursar en cuarto o quinto de carrera, yo la seleccioné en quinto. $Y$ una vez finalizada, el profesor, que era el responsable del servicio de medios audiovisuales del Instituto de Ciencias de la Educación de la Universidad de Sevilla, me comentó si quería colaborar con él. $\mathrm{Y}$ ya empecé a dar cursos de formación del profesorado. Así que, realicé los cursos de doctorado y la tesis doctoral en esa línea.

\section{2. ¿Desde cuándo se inició en la capacitación docente y cuáles han sido sus mayores retos?}

Prácticamente casi a los dos años de finalizar la licenciatura, ya que una de las funciones del Instituto de Ciencias de la Educación era, por una parte, impartir el "Certificado de Aptitud Pedagógica" y allí había una asignatura de Tecnología Educativa y además se daban cursos específicos. 
Los retos han sido diversos, y yo los centraría, por una parte, en la creación del "Secretariado de Recursos Audiovisuales y Nuevas Tecnologías" de la Universidad de Sevilla (http://sav.us.es), ya que no existían, y hoy en día es prácticamente lo mismo, centros que se dedicaran a la producción de recursos audiovisuales y nuevas tecnologías. Además de crearlo desde cero, mantenerlo en un mundo tan cambiante y dinámico como es el de las TIC. Por otra, fue la creación de las Asociación Edutec (Asociación para el Desarrollo de la Tecnología Educativa y de las Nuevas Tecnologías Aplicadas a la Educación) (htpp://www.edutec.es), asociación sin fines de lucro que une a docentes relacionados con la Tecnología Educativa de diferentes países del mundo, y que cada año organiza un evento en España y al año siguiente en un país Latinoamericano. Llevamos ya XXIII eventos, el próximo se hará en la universidad de Málaga. Incluso una vez se hizo uno en la República Dominicana.

Cada vez que empiezo un proyecto de investigación supone un reto: cómo lo vas a diseñar, qué instrumentos vas aplicar, cómo hacerlo operativo, qué grado de aporte científico tendrán los resultados.

\section{3. ¿A cuántos países ha viajado llevando el mensaje de la necesidad de que los maestros sean innovadores y adquieran las competencias tecnológicas?}

Afortunadamente son bastantes, en Latinoamérica, creo que solo me faltan por haber impartido alguna conferencia o acción formativa en Uruguay, Guatemala y Honduras. En el resto he desarrollado desde programas de doctorado, participaciones en Congresos, u otras actividades de formación.

Ser miembro del Consejo Directivo de la "Asociación de Televisión Educativa" Latinoamericana, me ofreció también la oportunidad de tener buenos amigos en diferentes países.
4. ¿Cuáles son los proyectos que lleva a cabo dentro y fuera de España que le han dado mayor satisfacción al colaborar con la capacitación en los medios tecnológicos?

Son diversos, por ejemplo los programas de doctorado que impulsamos en distintas Universidades de México (Autónoma de Tamaulipas y Durango), Venezuela (Carabobo y Metropolitana), en Chile (Mayor), Bolivia (Juan Michael Saracho) o República Dominicana (UPHEC); han sido experiencias satisfactorias pues me ha permitido contribuir con la formación de personas que después has visto que han formado a otras o que ya están llevando programas de investigación de alto impacto, como por ejemplo el proyecto DEREMARA (http:// proyectoderemara.com/) que lidera la Dra. Ivanovnna Cruz.

Los asesoramientos que realicé en Chile en la Universidad de Playa Ancha, donde se creó una Unidad de Mejoramiento Docente, fue una experiencia interesante. Desgraciadamente como ocurre muchas veces en Latinoamérica, hay cambio de autoridades y hay cambios de proyectos.

En la actualidad, estoy dirigiendo un proyecto de investigación muy interesante para la creación de t-MOOC formativos de los docentes en Competencias Digitales Docentes en España y un proyecto de investigación en México sobre la adicción de los adolescentes a las redes sociales que me está ofreciendo la oportunidad de verlas desde otra óptica.

\section{5. ¿Cómo ha logrado vencer la tecnofobia de los docentes veteranos que muestran resistencia a la tecnología educativa?}

Haciéndoles comprender que el esfuerzo inicial que invierten, después les será 
recompensado fuertemente en la realización de las tareas siguientes. Los docentes deben comprender que la tecnología no implica que tengan que ser tecnólogos instrumentales de las tecnologías, sino profesores que son capaces de sacarle un buen partido al uso educativo de las tecnologías. La resistencia al cambio viene muchas veces por la inseguridad que el docente siente hacia las tecnologías, esa es la primera barrera que hay que eliminar. $Y$ después debemos hacerlos reflexionar, como pone de manifiesto la investigación, por qué un docente en sus distintas actividades sociales y familiares sí usa las tecnologías y como recurso para su actividad docente, no. Las instituciones educativas deben estimular el uso continuo de los recursos tecnológicos, deben también respaldar a sus docentes, capacitarlos y facilitarles el acceso a las plataformas.

\section{6. ¿Por qué debemos considerar las competencias tecnológicas como fundamentales y como componente esencial de la innovación educativa?}

Simplemente, porque la educación debe capacitar a los ciudadanos para desenvolverse en el mundo en el que vive y en el futuro en el cual se desenvolverá. Aunque en este último caso, la complejidad en la cual nos vamos a desenvolver hace que sea muy difícil imaginarlo. $Y$ eso siempre ha sido así en la educación. Antes, la persona alfabetizada era la que dominaba la lectura y escritura, puesto que el medio básico de comunicación era el impreso. Hoy, la taxonomía de medios que utilizamos se ha ampliado, por tanto, debemos dominarlos para comunicarnos. $Y$ esa fuerte presencia tecnológica hace que aprendamos de otra manera, y en esa forma de aprender, las tecnologías digitales juegan un fuerte papel. Sería absurdo formar a estudiantes de la sociedad del conocimiento y la cuarta revolución industrial, con tecnologías de la sociedad industrial.

\section{7. ¿Cuáles son las ventajas y desventajas de la educación totalmente virtual?}

Yo no soy muy partidario del discurso de las ventajas y desventajas de las tecnologías, ya que todo depende del uso que hagamos de ellas y del contexto en la cual las vamos a movilizar. Lo que sí creo que debemos cambiar es el imaginario social e institucional universitario que lleva a los administradores educativos a creer que una enseñanza virtual on-line es de segunda clase. Lo importante no es que la educación sea presencial o virtual, sino que sea de calidad, movilizando recursos tecnológicos oportunos, fomentando, los docentes en la red, prácticas innovadoras y fortaleciendo la comunicación sincrónica y asincrónica entre profesor y estudiantes con las diferentes herramientas de comunicación sincrónicas y asincrónicas que tenemos a nuestra disposición. Por otra parte, puedo asegurar que la investigación está aportando datos de que los alumnos y profesores prefieren un modelo mixto, o de b-learning. Lo importante no es la distancia física entre el docente y el estudiante, sino su distancia cognitiva.

\section{8. ¿Cuáles son los pasos más recomendables para que se} logre de manera rápida y eficaz la capacitación de los docentes ante la emergencia que ha traído la pandemia Covid-19?

Hacerles esta formación fácil, en este sentido, la formación debe estar centrada en el uso educativo de las tecnologías, y no en el uso meramente instrumental. Las Universidades deben tener un centro de apoyo a los docentes para la incorporación emergente de estas tecnologías y que se ocupen de su desarrollo y capacitación. Me refiero a centros con una perspectiva del uso educativo de las tecnologías y la producción de recursos didácticos, independientemente de los centros que se 
refieran únicamente a mantener la red, la plataforma.

\section{9. ¿Cuál de los tres momentos del proceso de enseñanza- aprendizaje (planificación, tutelaje o evaluación) es el que más debemos prestarle atención para lograr un aprendizaje profundo y no superficial?}

A todos por igual, ese ha sido uno de los errores cometidos en la enseñanza. Por ejemplo, hacemos muchas prácticas innovadoras y después seguimos evaluando de forma totalmente tradicional $y$ sumatoria.

\section{0. ¿Cómo podemos lograr una evaluación del proceso que sea fiable y competente en la educación totalmente virtual?}

Debemos enfatizar la idea de una evaluación continua, una evaluación donde no analicemos lo aprendido por el estudiante con una única prueba. De todas formas, hay diferentes estrategias tecnológicas que facilitan el reconocimiento del estudiante y otras que permiten la aleatorización de las preguntas, los exámenes orales grabados por los estudiantes, etc.

\section{1. ¿Cuáles recursos, objetos y contenidos digitales son los más recomendables para mantener la calidad en el aprendizaje?}

De nuevo te diría que todos y ninguno. El mejor medio es aquel que en un momento dado le resuelve al docente los problemas de comunicación que pueda tener en ese momento con sus estudiantes. Pensar que un profesor es mejor que otro porque utilice una gran variedad de tecnologías es un error; es mejor que otros si con las tecnologías sabe crear entornos innovadores de enseñanza enriquecidos por las tecnologías. Todo está en cómo los usamos. $Y$ pongo un ejemplo, yo puedo utilizar el vídeo y crear clases completamente transmisivas y pasivas, pero puedo también crear escenarios innovadores, cuando hago que los alumnos, con la estrategia de la clase invertida, trabajen en su casa viendo un vídeo, con el cual tienen que hacer un informe siguiendo la estrategia 3-2-1: qué tres cosas han aprendido, cuáles dos dudas les ha creado y qué pregunta harían. $Y$ durante la clase hago que los alumnos planteen las preguntas que pueden ser respondidas por el docente o por sus pares. Finalmente, les pongo una tarea que deben resolver de forma colaborativa. Con una estrategia así ha cambiado todo, ella promueve un aprendizaje profundo y activo.

\section{2. ¿Cuáles recomendaciones nos ofrece para que tanto los docentes como los estudiantes no se saturen con la cantidad de trabajos de lectura-escritura y manejen con éxito el aula virtual?}

Ese es el gran problema que tiene el docente cuando se incorpora a la formación virtual. Y lo estamos viendo en estos duros momentos. En lo presencial, tenemos experiencia con el horario académico y sabemos desenvolvernos, en lo virtual, los docentes se suelen saturar. Yo diría que trabajen con dos ideas, la primera es: "cuánto menos, más"; y la segunda, que busquen los aspectos verdaderamente significativos de las competencias que tienen que adquirir sus estudiantes $y$ trabajen sobre ellas. 